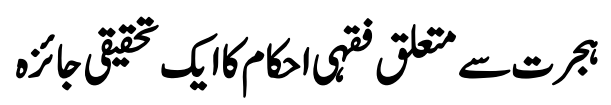

\title{
Critical Review of Justice Verdicts Regarding (Hijjrat) Migration
}

$$
\begin{aligned}
& \text { ثبان نورين }
\end{aligned}
$$

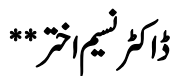

\begin{abstract}
Migration is an esteem worship and is the primary, significant and essential component of Islamic Sharia, that becomes the expression for framing the ideology, deeds and actions of the believers. Emigration does not merely mean translocation but it is indeed defying the limits that have restricted human imagination. Emigration is doing away with all these boundaries and entering new horizons of freedom. It is the concept of migration that has provided strength to the idea of Jihad (holy war) which in turn inculcates the quality of sacrificial deeds in human beings in the presence of which they whole heartedly sacrifice even their lives to please the Almighty Allah. It is based on it that Islamic Jurists have devised various Islamic rulings regarding migration in the light of Qura'an and Hadith. Therefore in this article given are some of the important points of Islamic Jurists in this regard.
\end{abstract}

Key Words: Migration, Islamic Sharia, Ideology, Islamic Jurists, Qura'an, Hadith.

$$
\begin{aligned}
& \text { جمركى لغوى تّر ليف }
\end{aligned}
$$

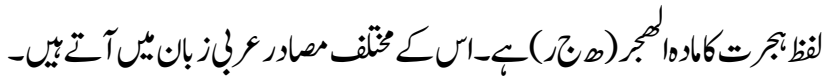

$$
\begin{aligned}
& \text { ״الهاء و الجيم و الر اء أصلان يدل أحدهما على قطيعة وقطع، والآخر على شد شيء } \\
& \text { وربطه.فالأول الهجر: ضد الوصل و كذلك الهجران. وهاجر القوم من دار إلى دار: }
\end{aligned}
$$

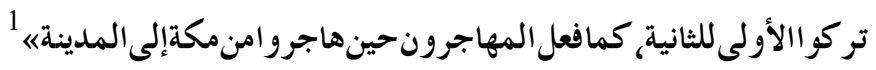

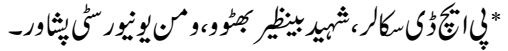

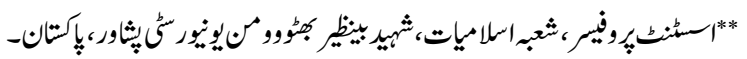




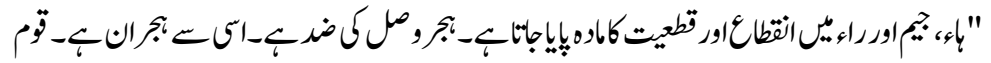

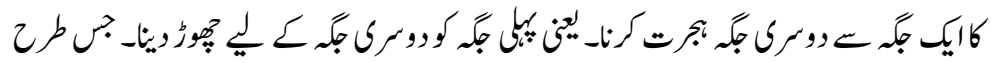

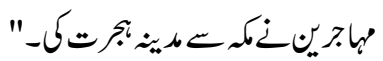

$$
\begin{aligned}
& \text { علامدرانب|صنها أكلكمبيك: }
\end{aligned}
$$

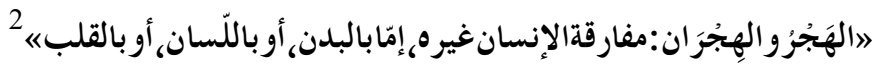

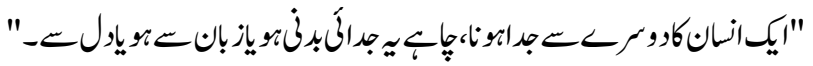

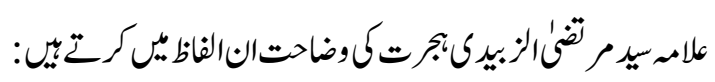

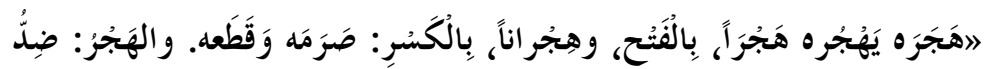

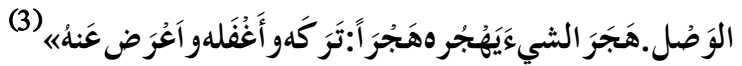

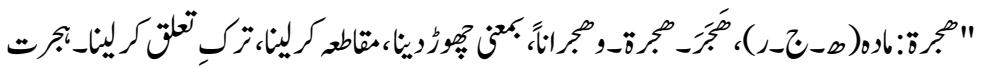

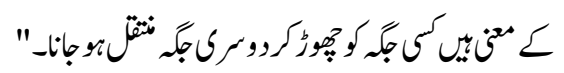

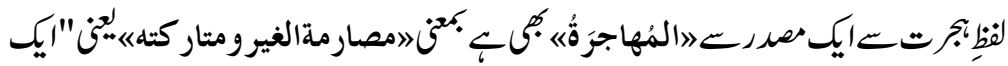

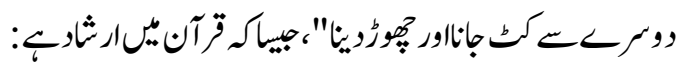

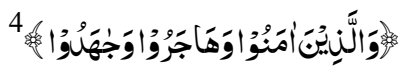

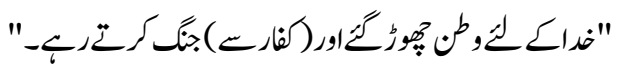

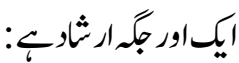

5

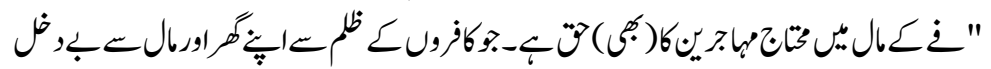

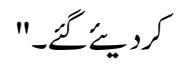

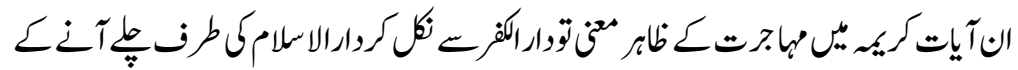

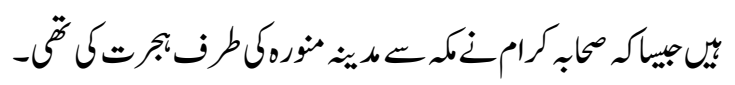

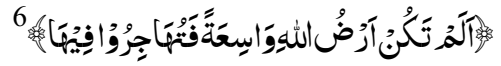

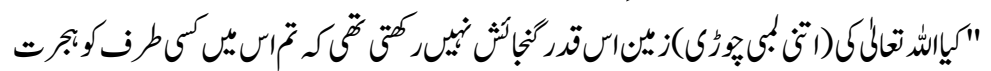

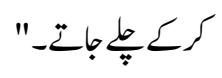




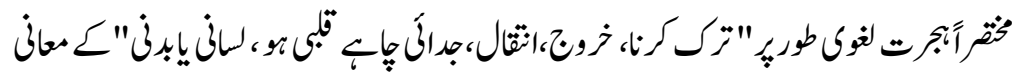

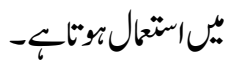

\section{نجمتركاصطارق تخ ليف}

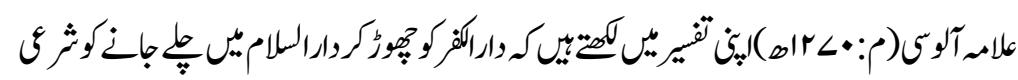

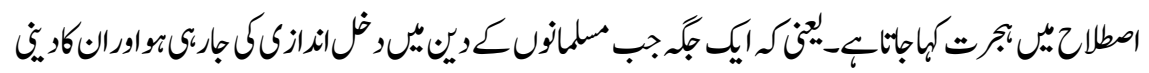

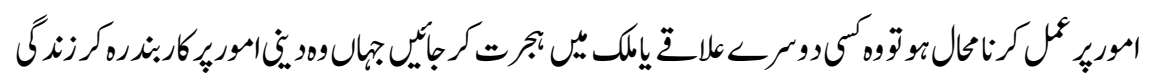

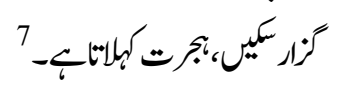

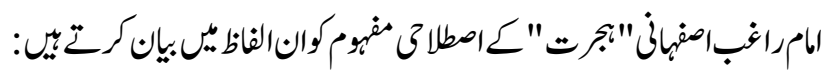

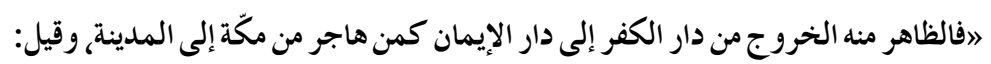

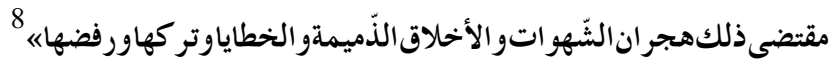

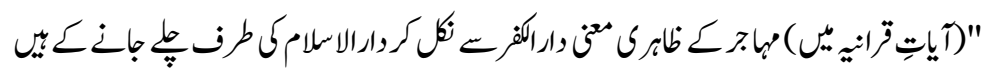

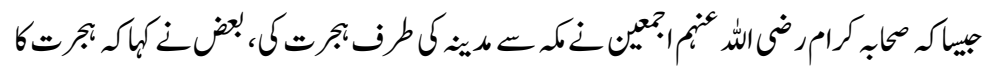

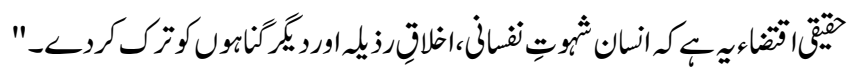

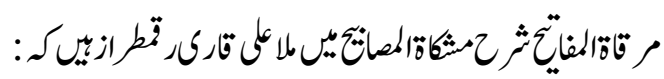

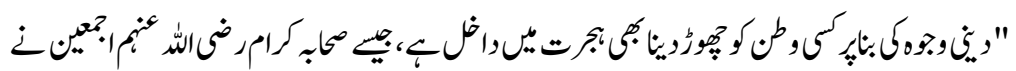

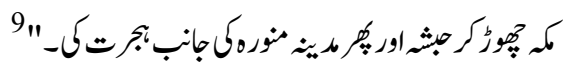

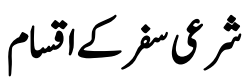

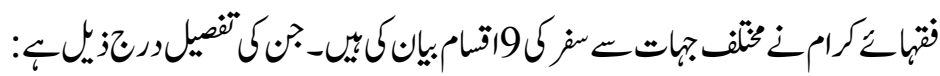

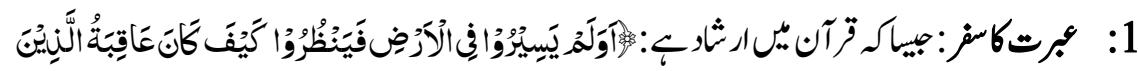

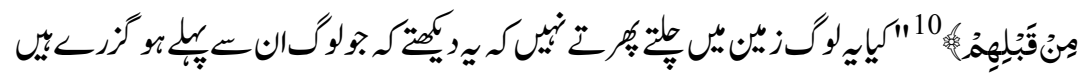
انكاكيارنجامبوا-

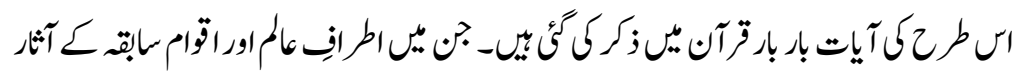




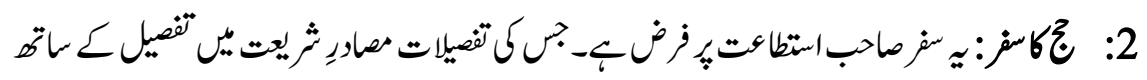

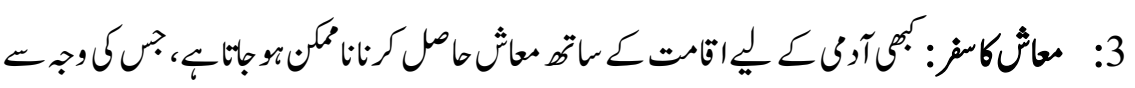

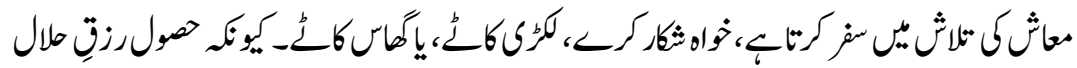

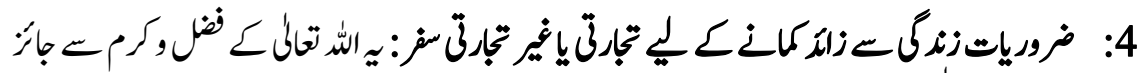

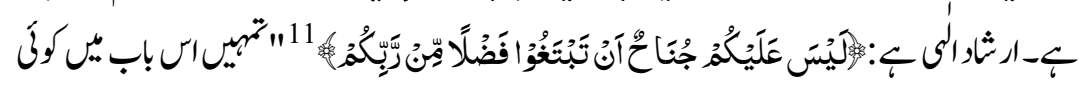

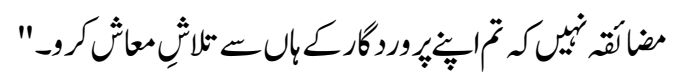

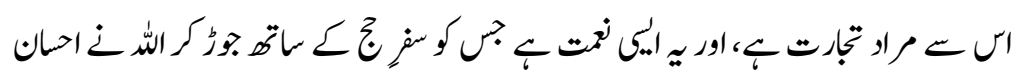

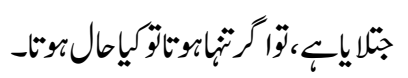

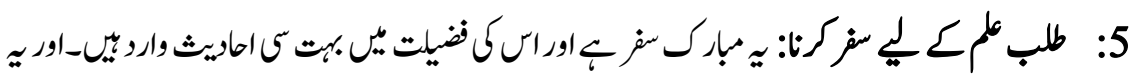

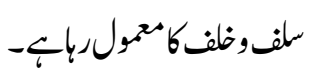

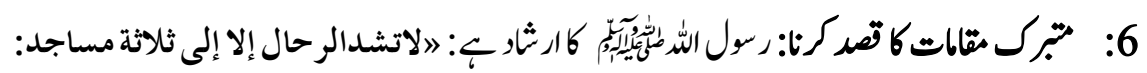

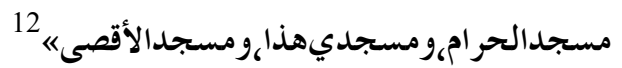

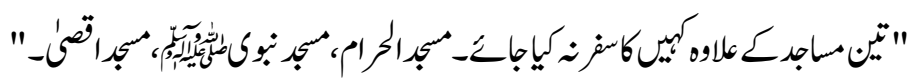
7:

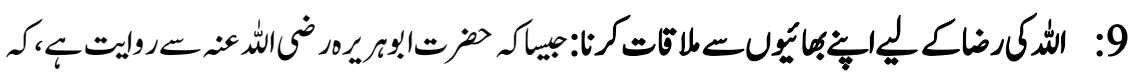

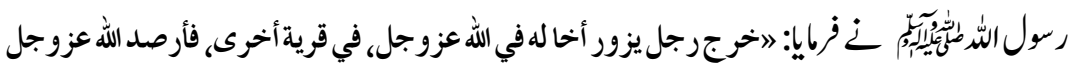

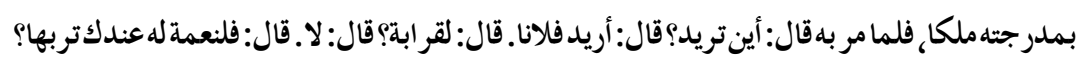

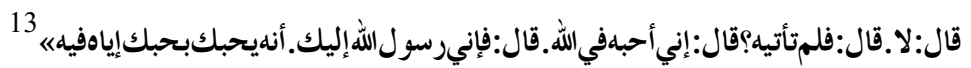

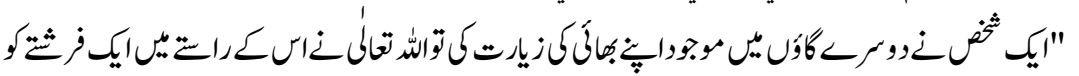

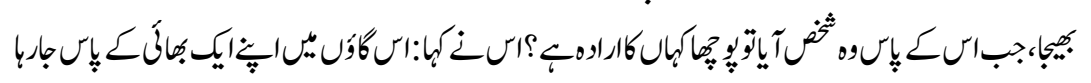

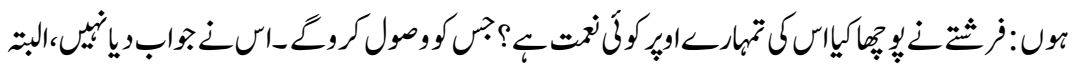

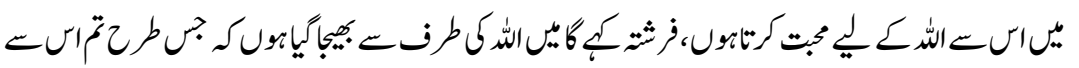

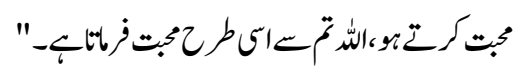




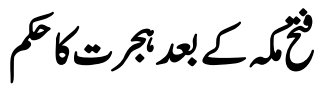

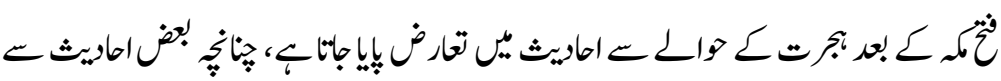

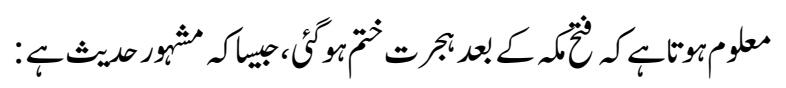

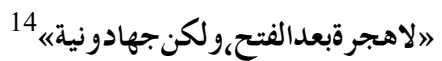

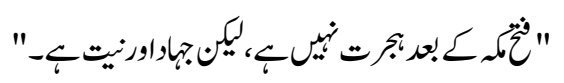

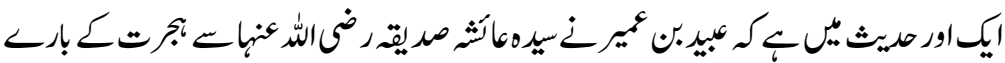

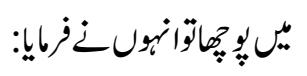

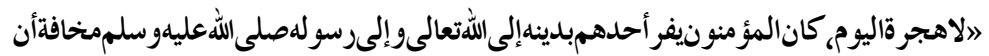

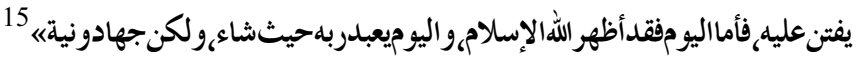

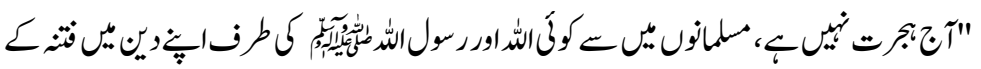

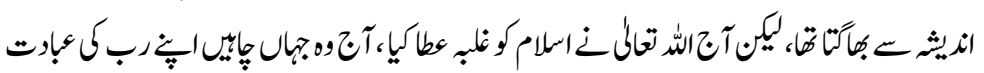

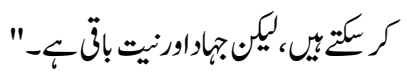

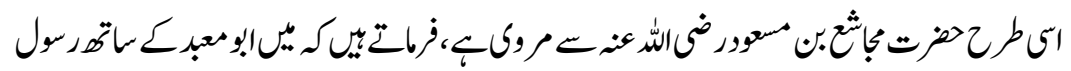

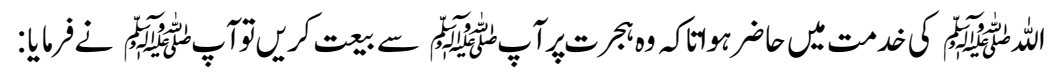

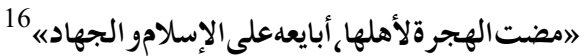

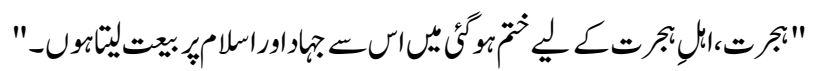

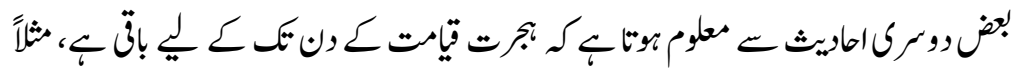

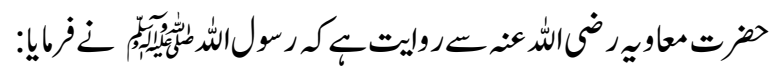

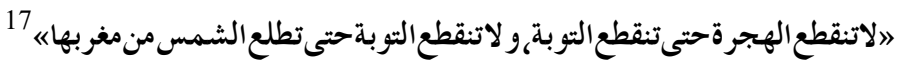

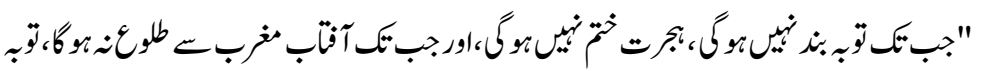

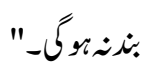

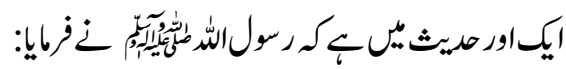

"إن الهجرة لاتنقطع ماكان الجهاده 18

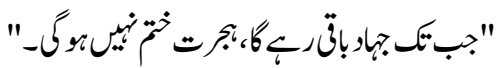




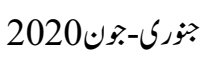

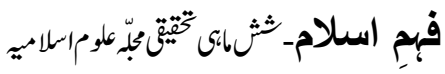

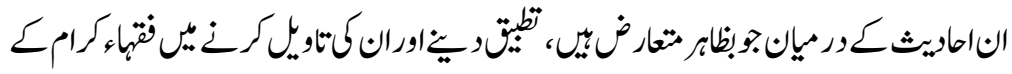

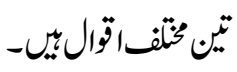

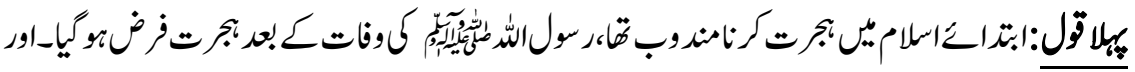

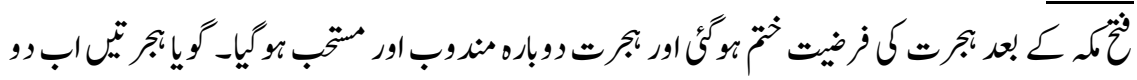

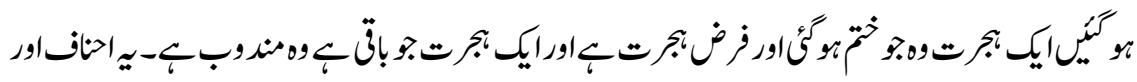

19 خطإكاقولى

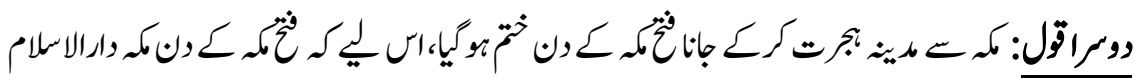

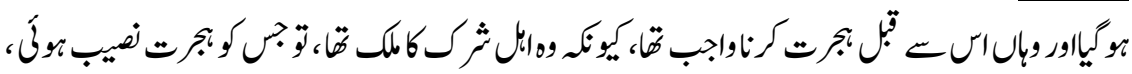

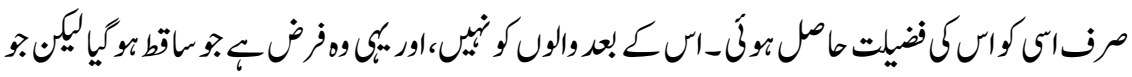

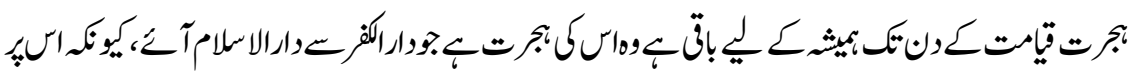

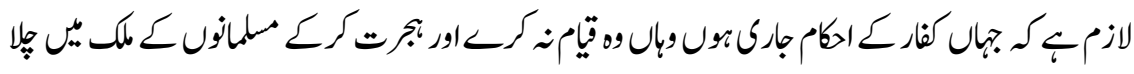

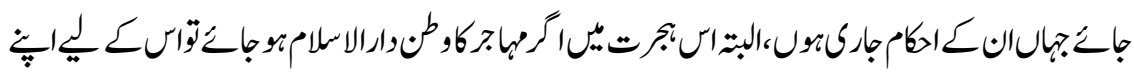

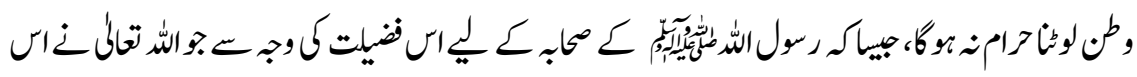

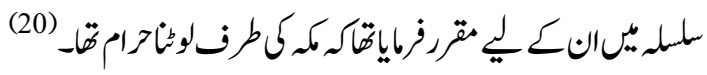

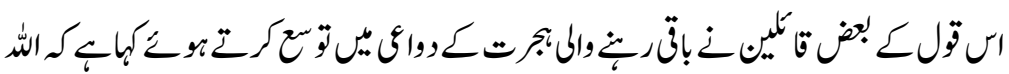

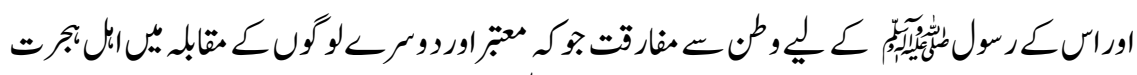

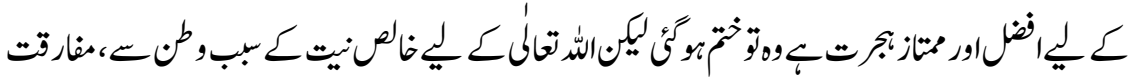

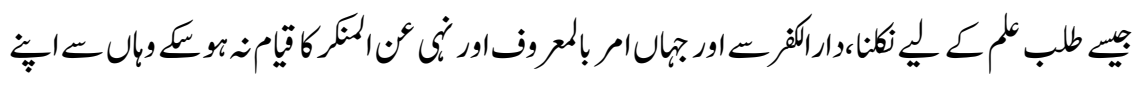

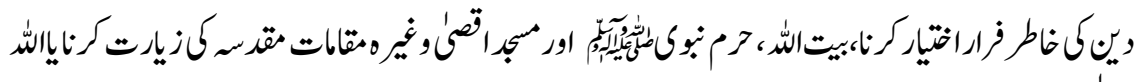

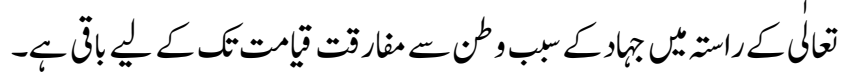

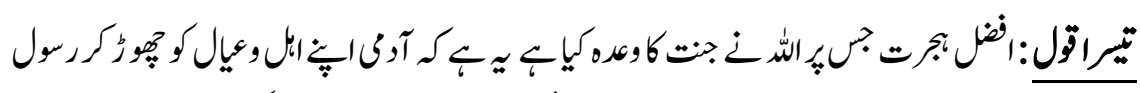

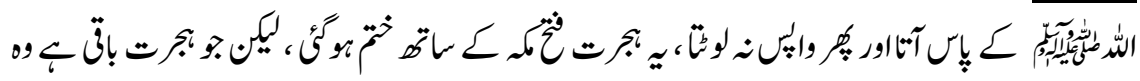

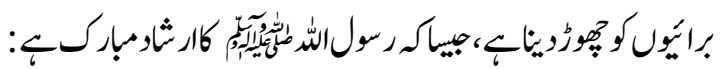

194 
”إن الهجرةخصلتان: إحداهمأنتهجر السيئات، والأخرى أنتهاجر إلى اللهو إلىرسوله، لاتنقطع الهجرةماتقبلت التوبة،ولاتز ال التوبةمقبولةحتى تطلع الشمس من المغرب، فإذاطلعت طبع على كلقلب بمافيه، وكفي الناس العمل « 21

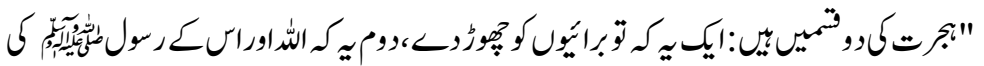

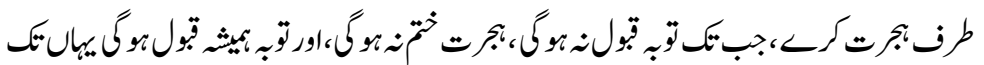

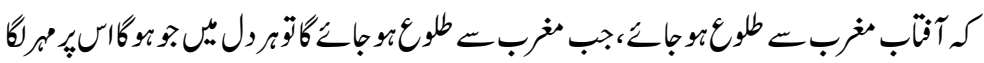

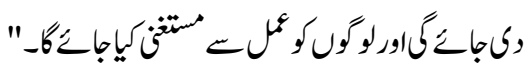

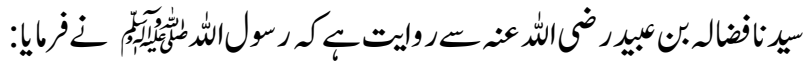

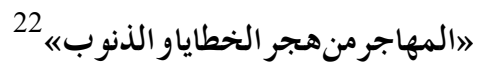

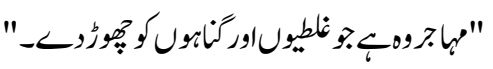

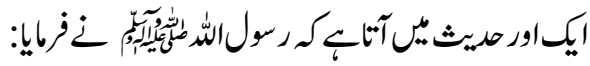
"المهاجرمن هجر مانهى اللهعنه 23

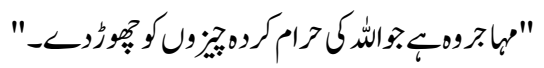

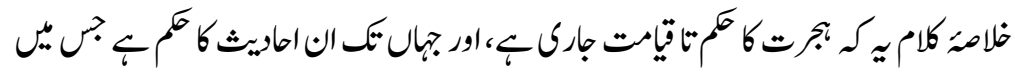

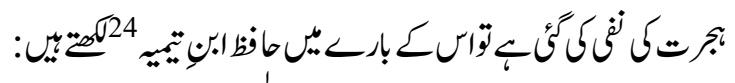

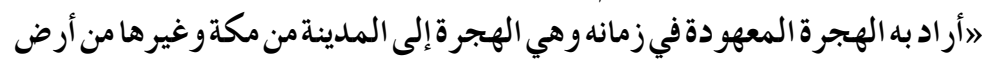

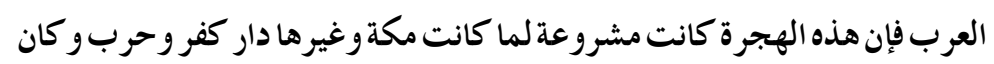

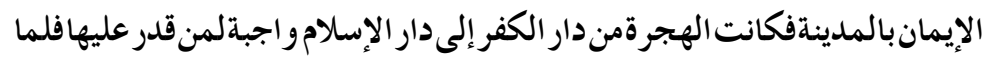
فتحت مكةوصارت دار الإسلامه 25

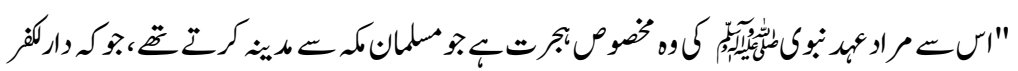

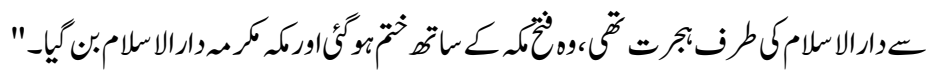

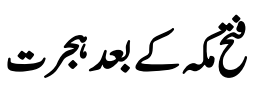

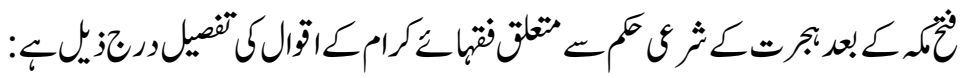




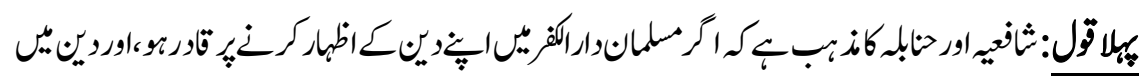

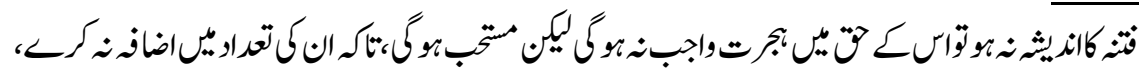

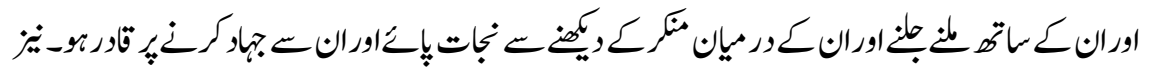

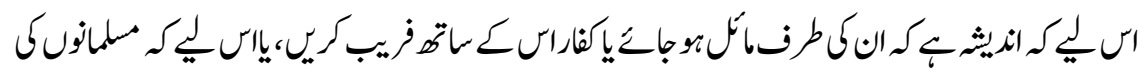

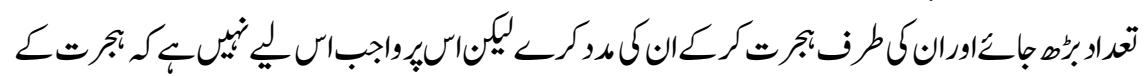

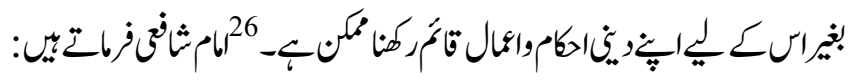

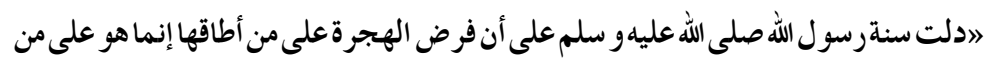

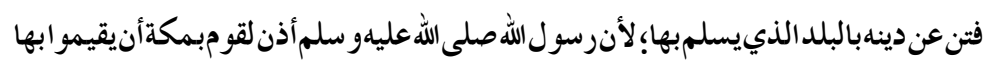

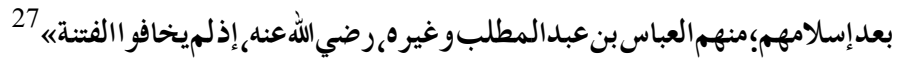

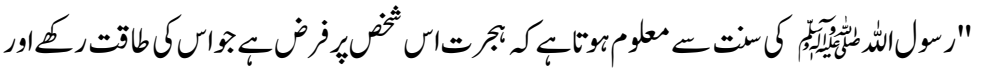

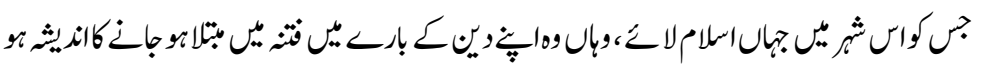

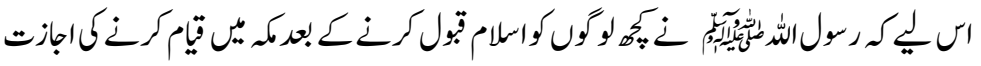

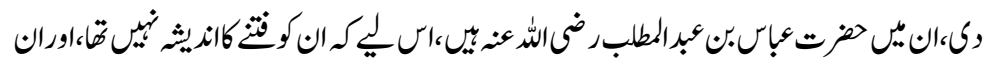

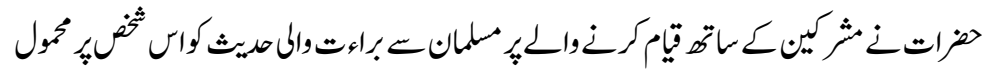

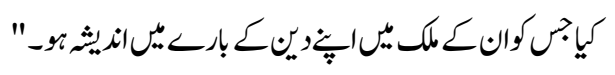

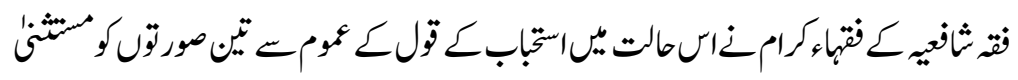

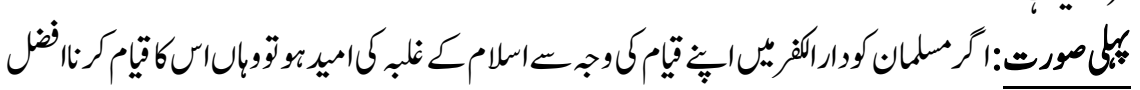
$-\frac{1}{6}$

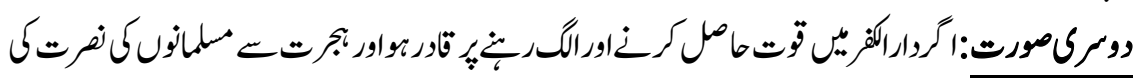

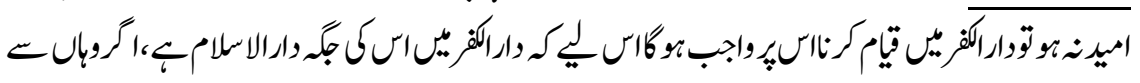

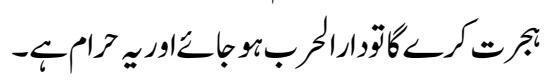

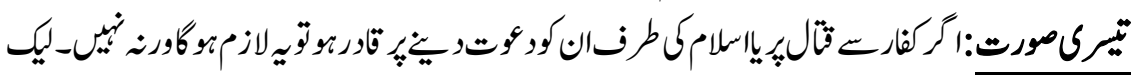

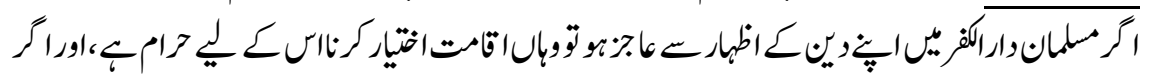


r 


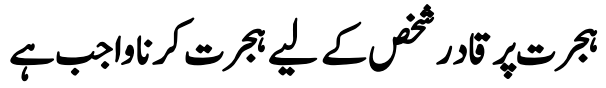

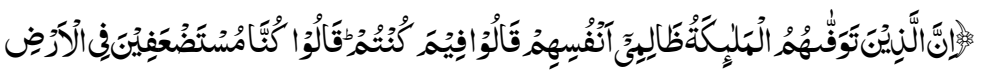

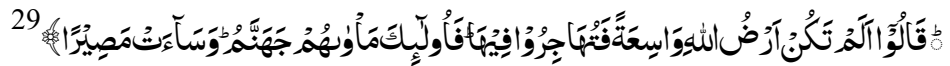

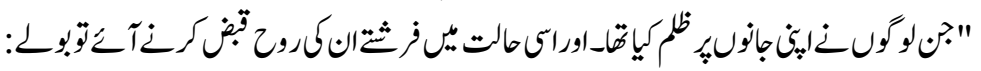

تم كسالتئس

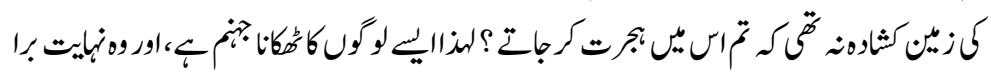

انجامب--

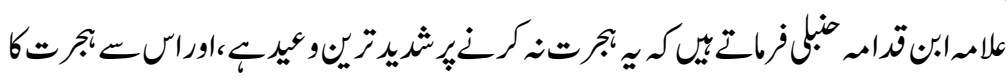
وجوبثابت

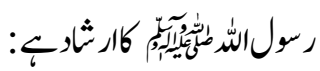

״أنا بريء من كل مسلم يقيم بين أظهر المشركين. قالو ا يارسول الله، ولم؟ قال: لا تراءى



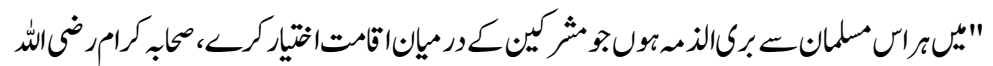

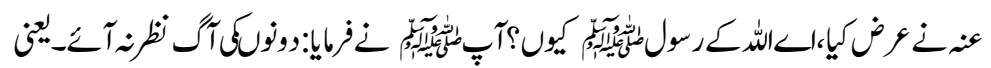

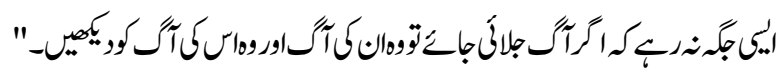

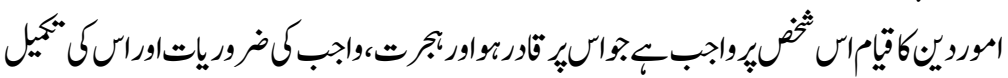

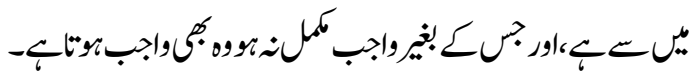

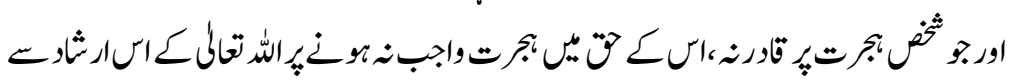

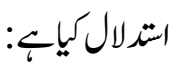

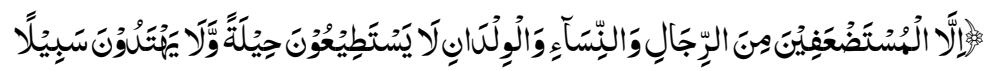

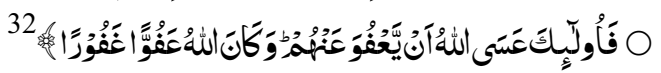

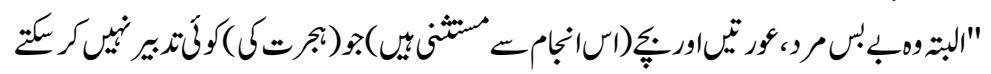

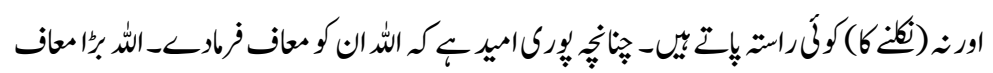

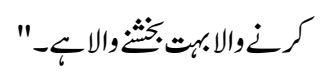




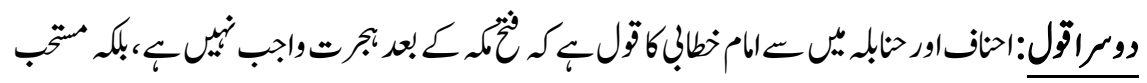

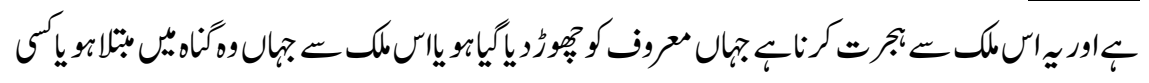

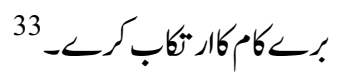

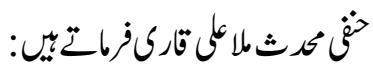

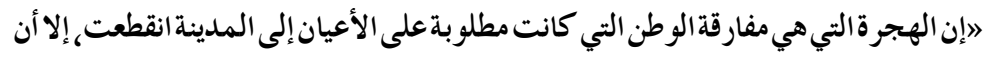

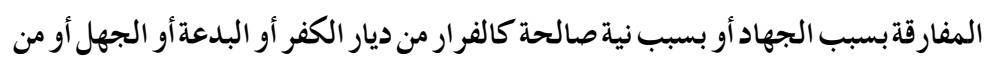

$$
\text { الفتن أو لطلب العلمباقيةغير منسوخةهابل } 34
$$

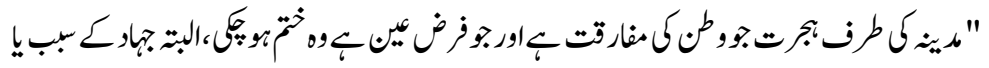

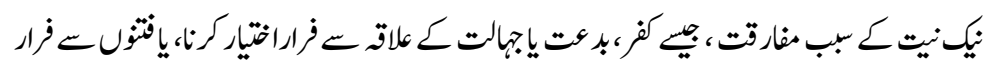

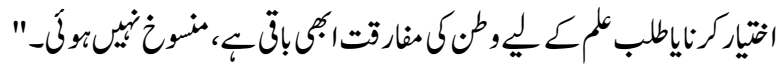

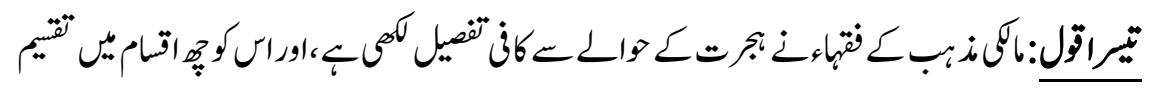

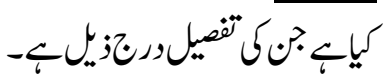

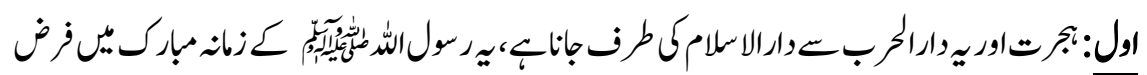

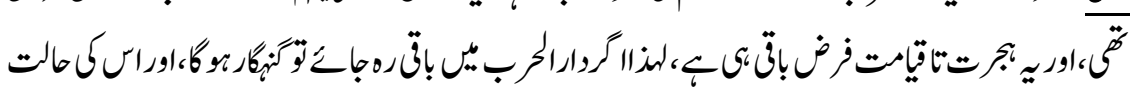

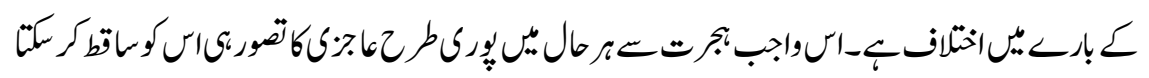

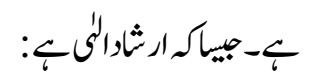

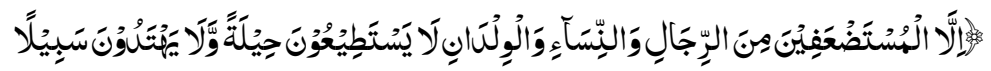

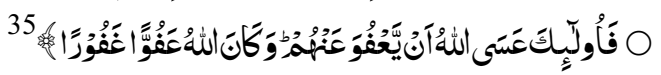

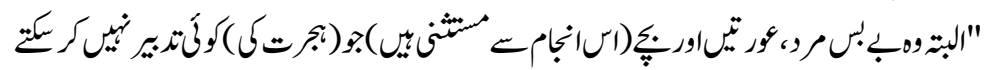

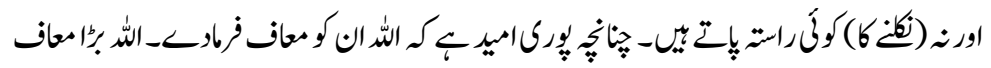

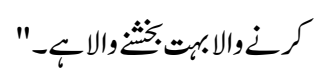

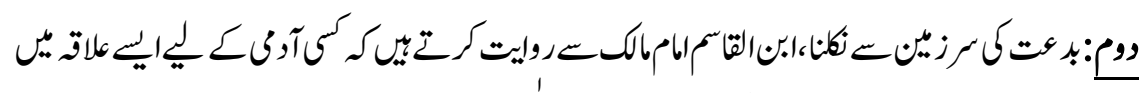

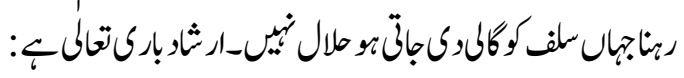




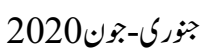

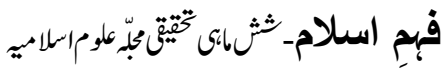

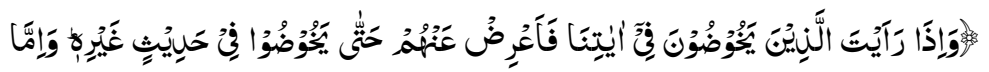

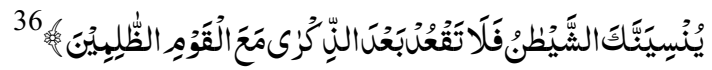

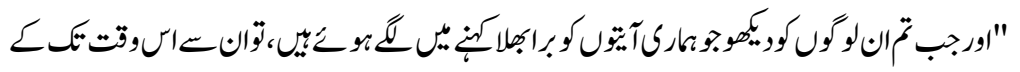

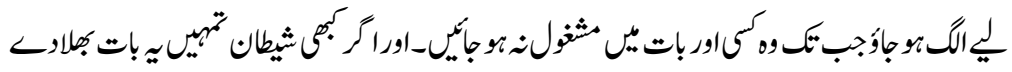

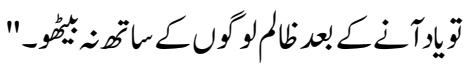

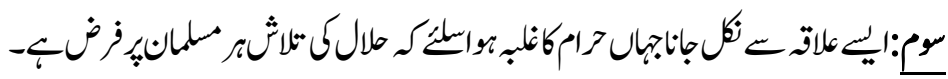

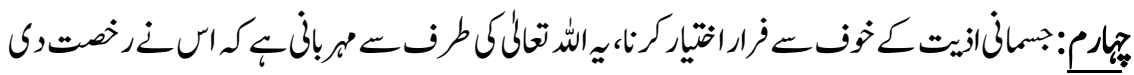

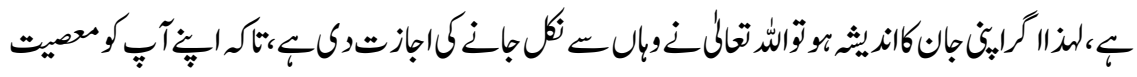

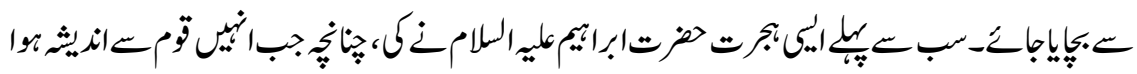

توزمايا:

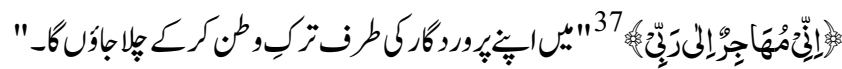

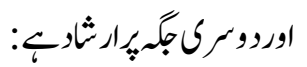

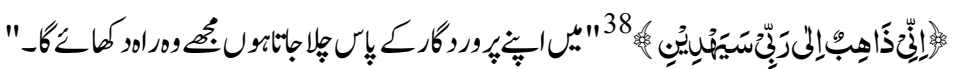

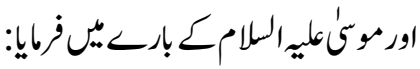

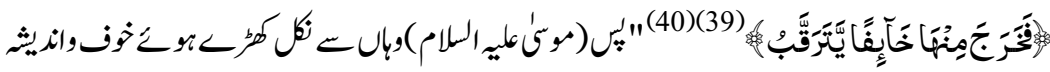

ك

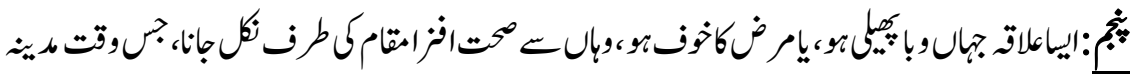

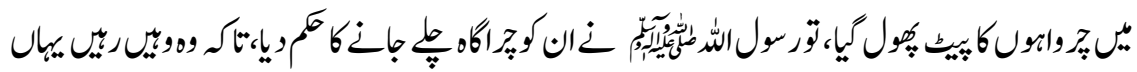

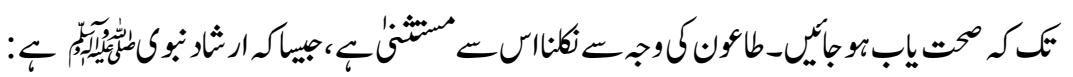

"إذاسمعتمبالطاعونبأرض فلاتدخلو هاو، إذاوقعبأرضو أنتمبهافلاتخر جو امنهاهي 41

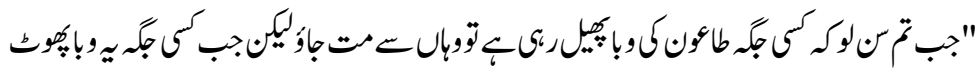

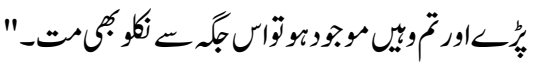

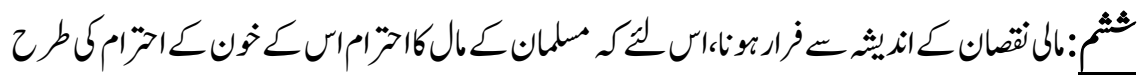

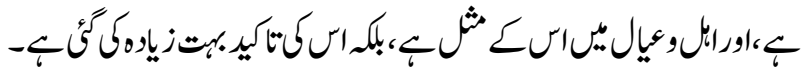

199 


\section{وارالكز ع ورتكم:جرت}

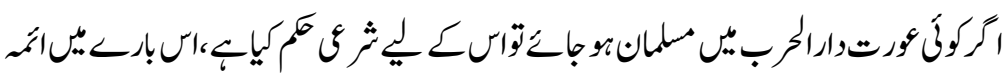

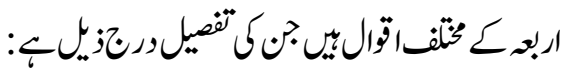

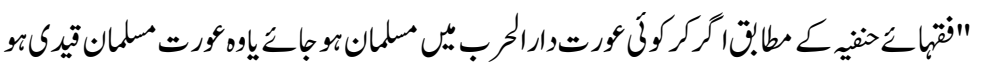

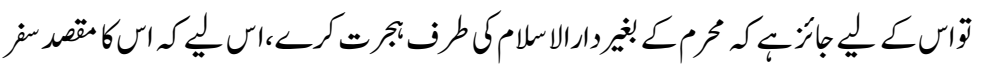

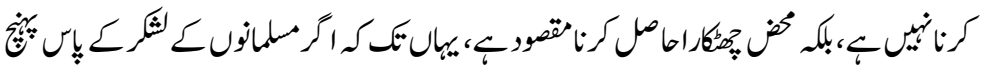

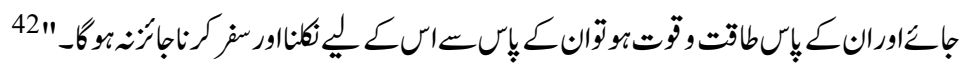

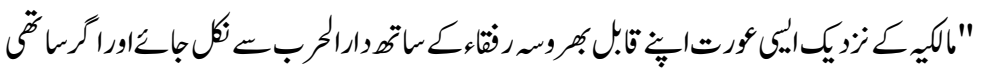

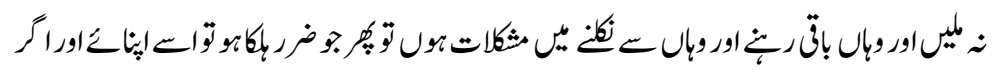

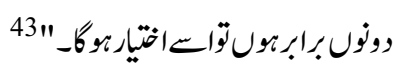

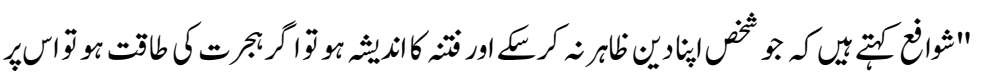

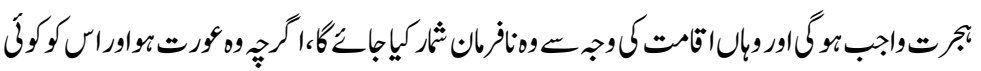

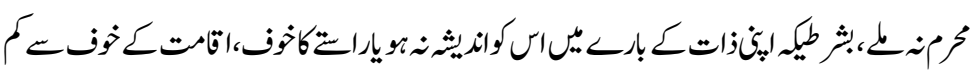

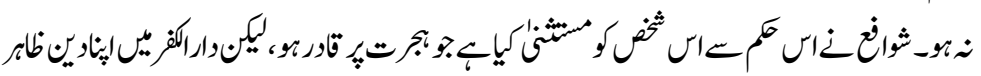

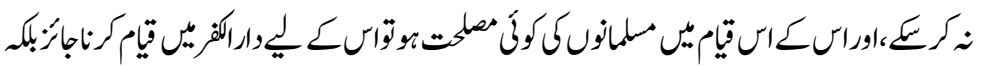

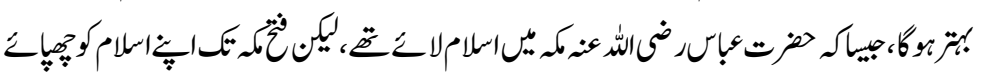

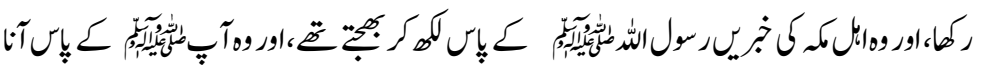



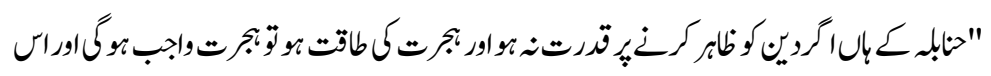

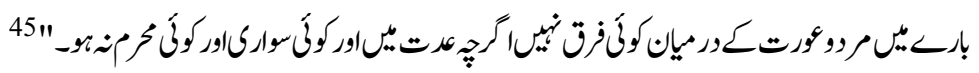

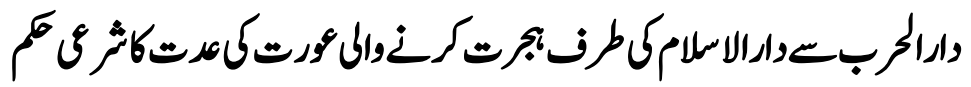

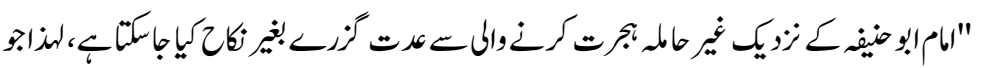

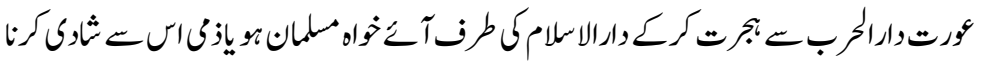

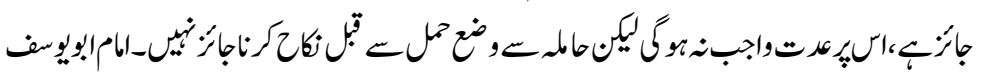




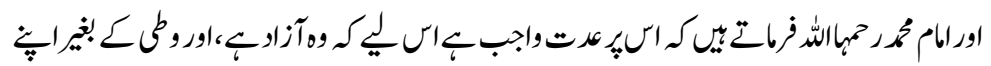

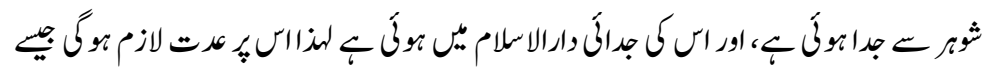

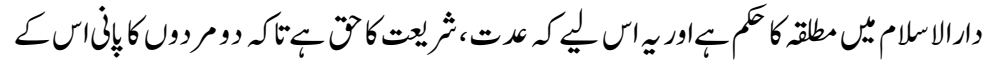

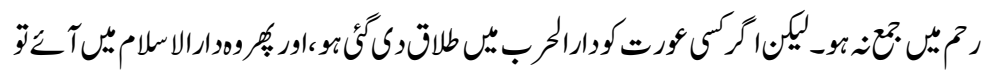

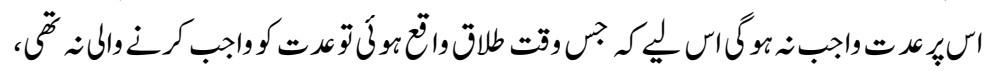

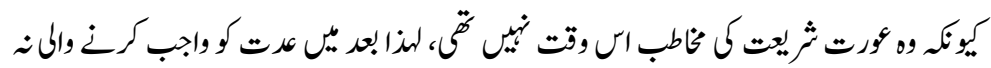

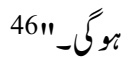

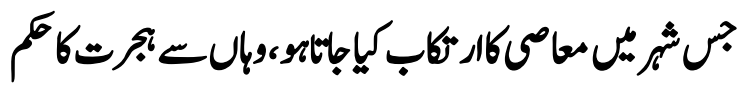

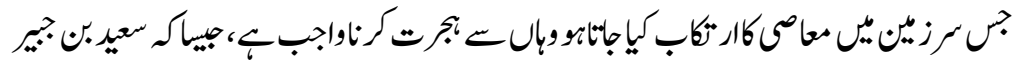

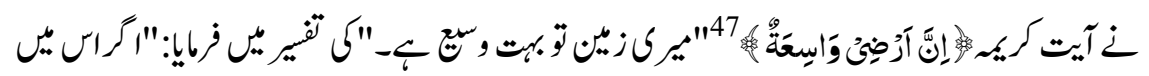

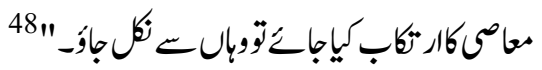

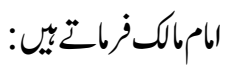

" 49 "الايحلل أحدأنيقيم ببلديسبفيهالس

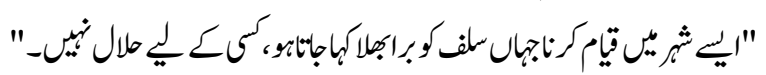

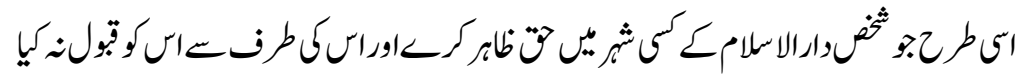

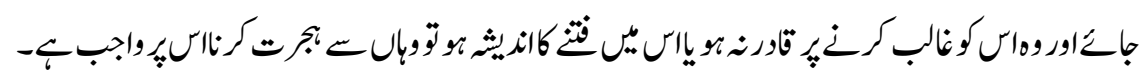

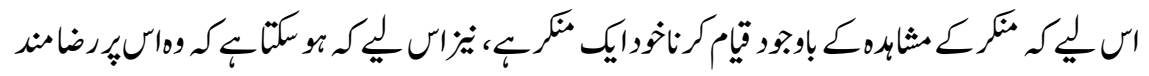

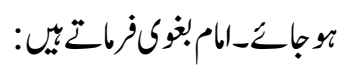

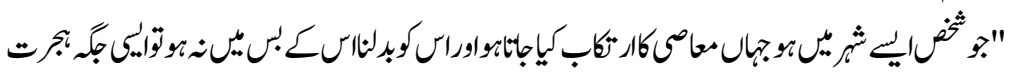

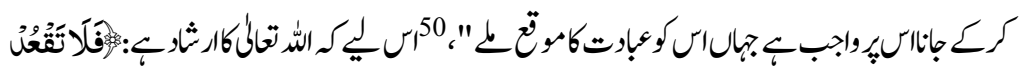

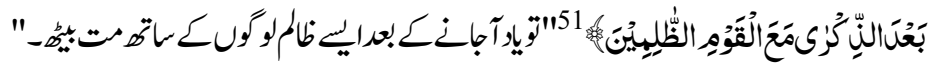

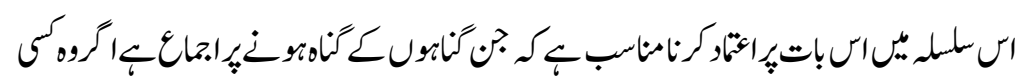

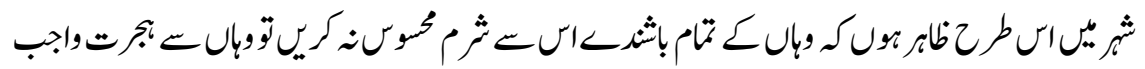




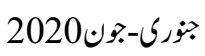

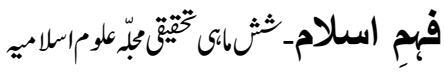

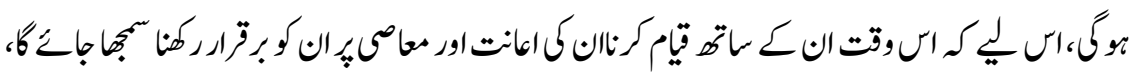

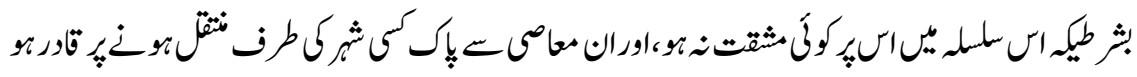

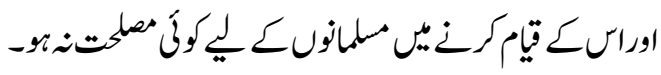

$$
\text { وارالحربــ مثلقتاحكم }
$$

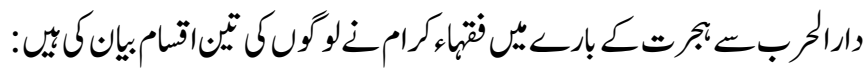

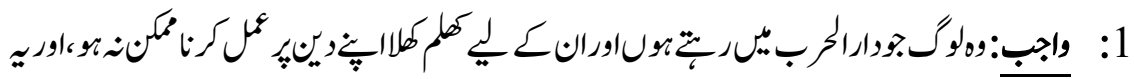

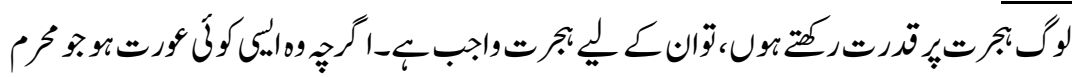

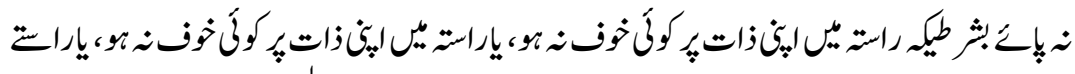

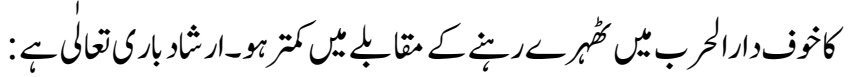

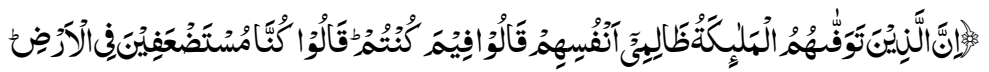

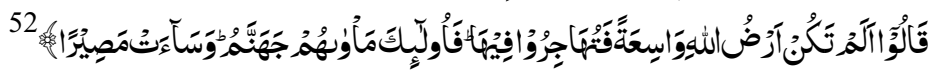

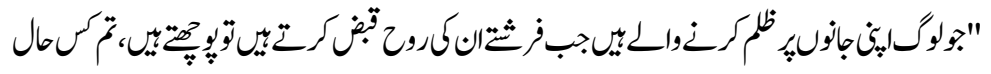

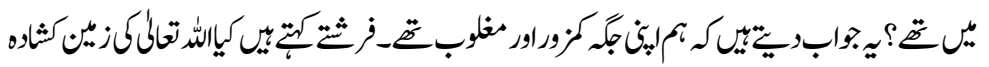

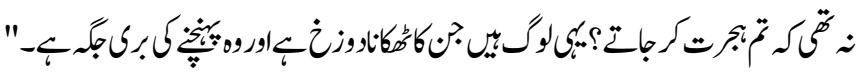

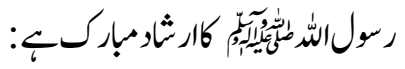

"أنابريءمن كل مسلميقيم بين أظهر المشر كين لاتتر اءىنار اهماه 53

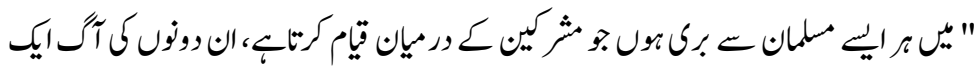

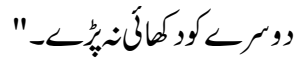

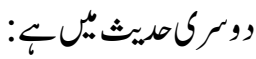

" 54 "لاتنقطع الهجرةمادام العدويقاتل

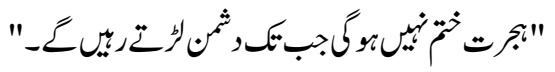

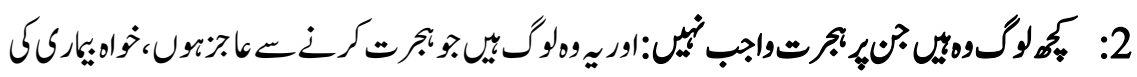

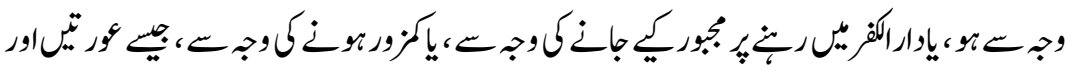

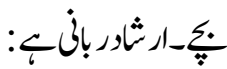

202 
55 每

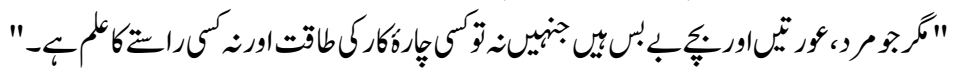

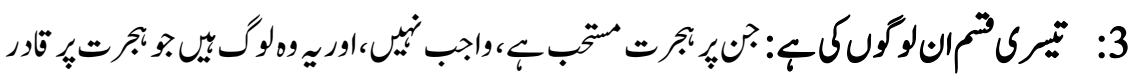

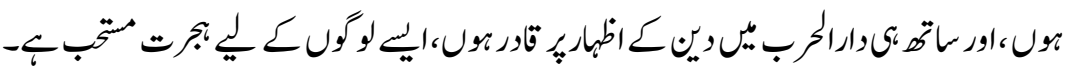

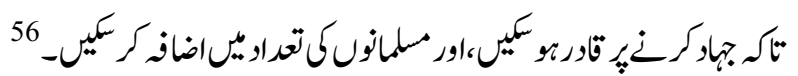

\section{ملام كلمام}

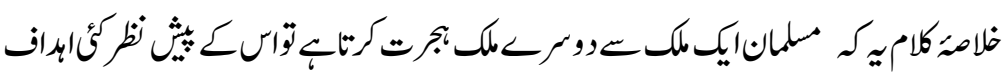

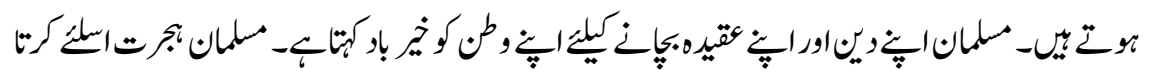

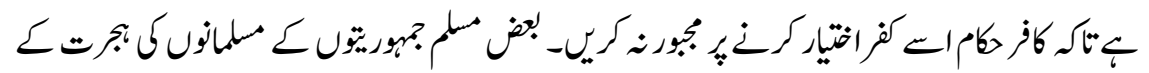

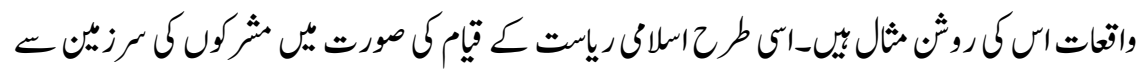

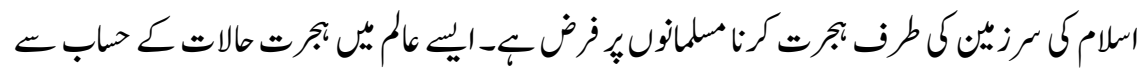

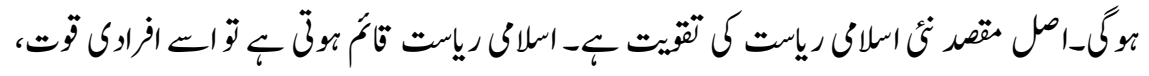

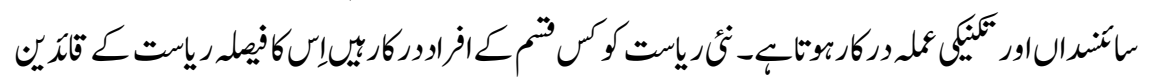

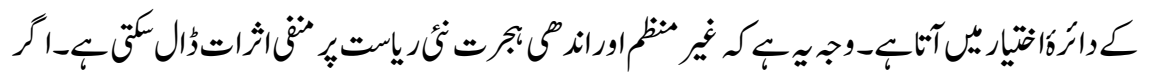

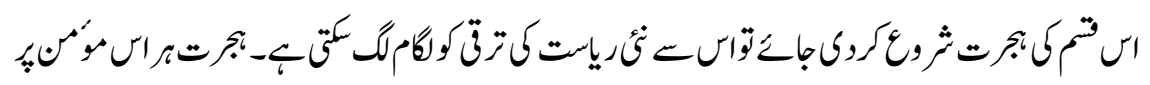

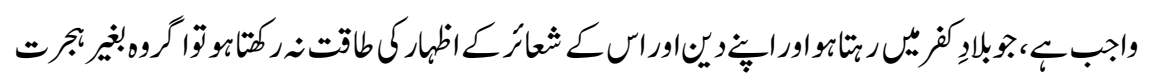

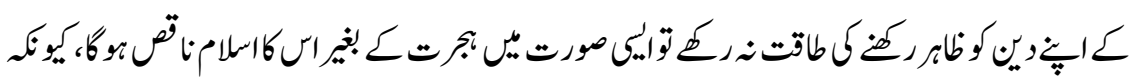

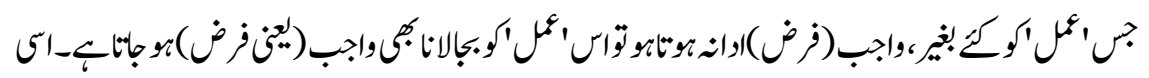

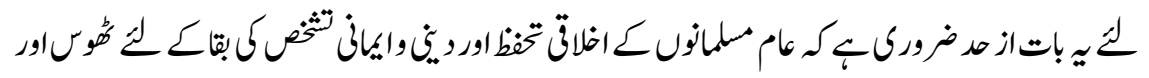

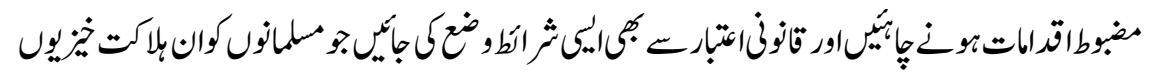

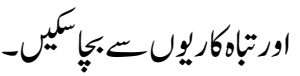




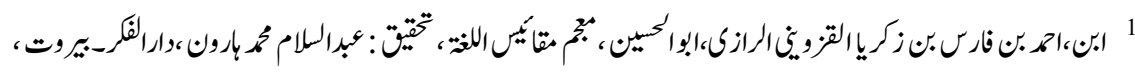
$-M 4 \rho .4 ? \times 19<9$

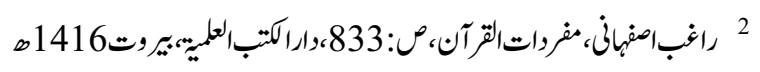

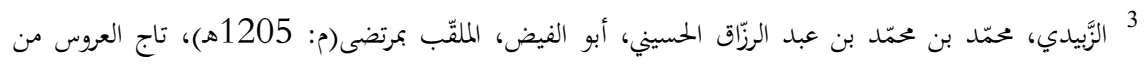

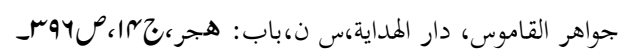
4 5 6

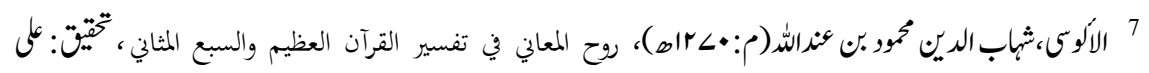

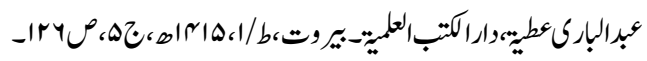

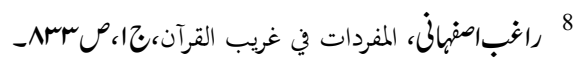

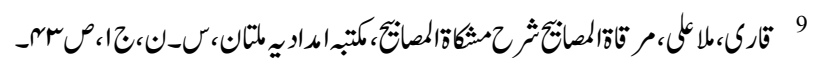

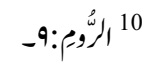

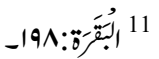

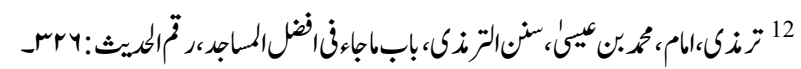

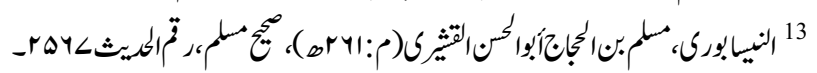

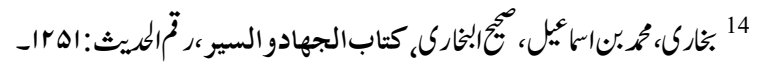

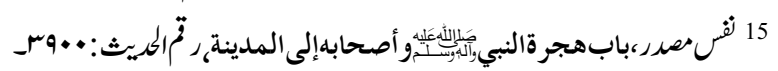

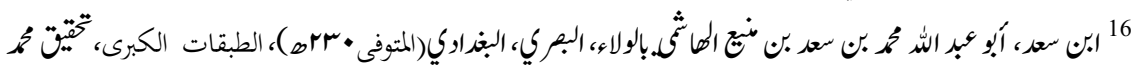

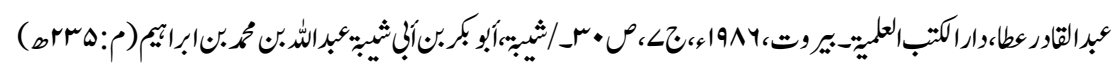

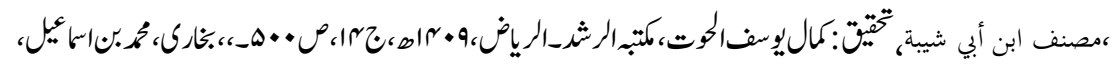

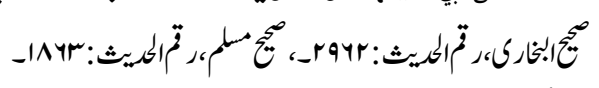

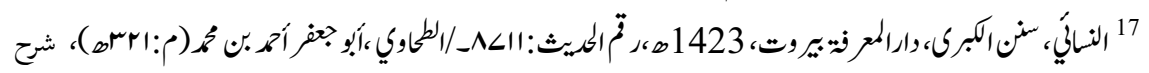

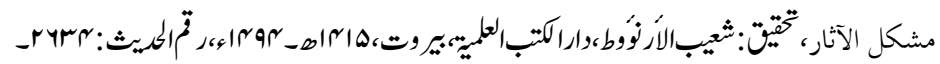

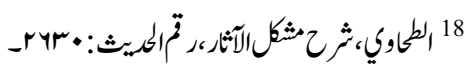




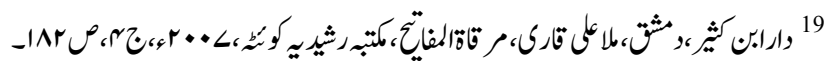

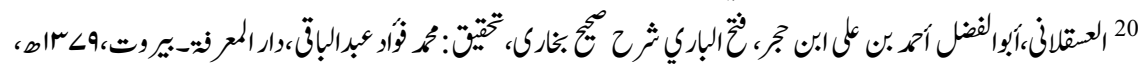
-

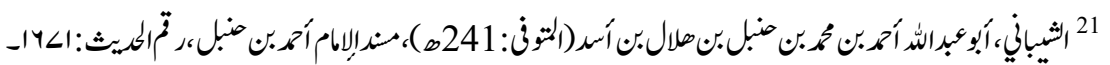

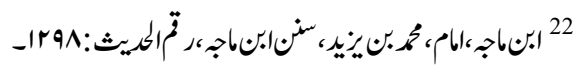

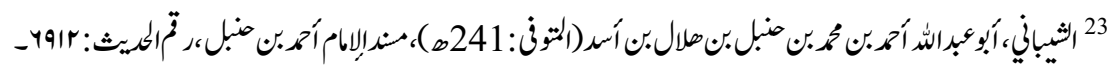

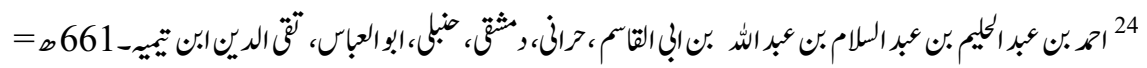

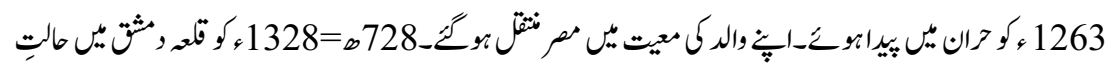

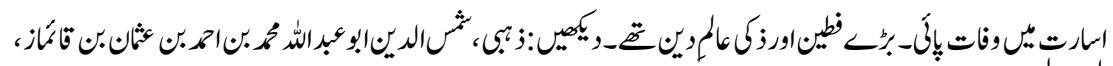

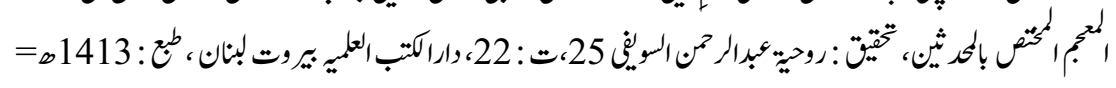

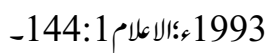

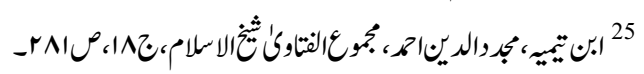

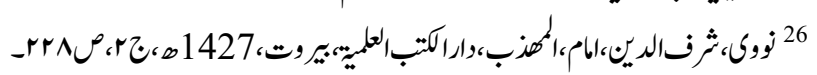

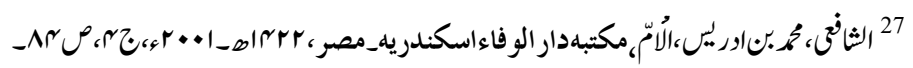

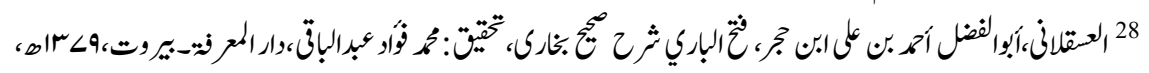
rav.4? 29 النسا: 29

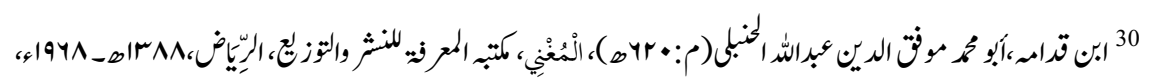

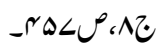

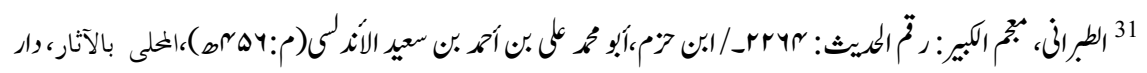

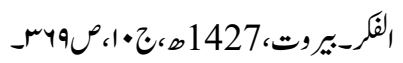

32

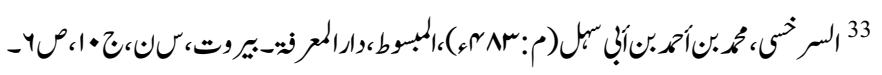


35

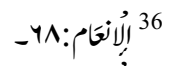
37 


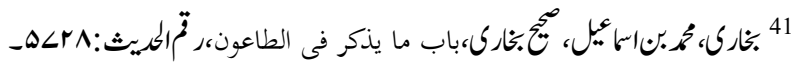



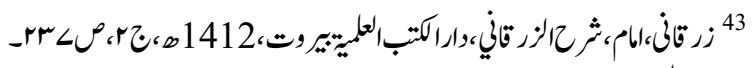

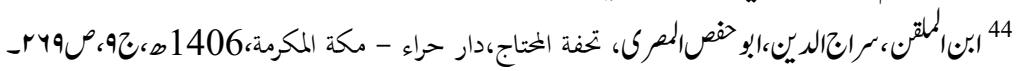

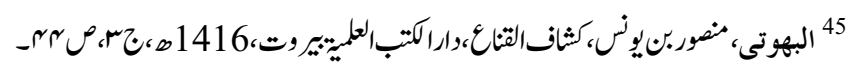

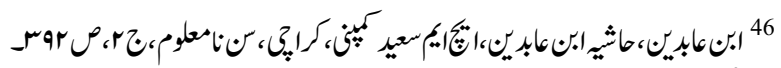
47

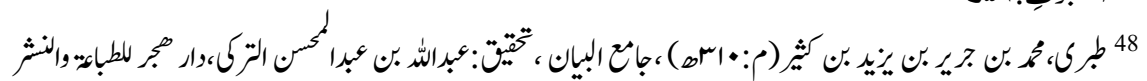

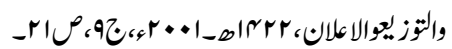

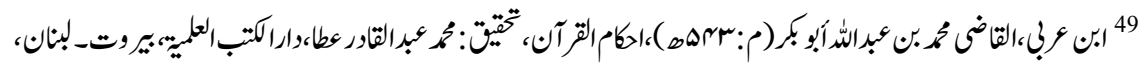

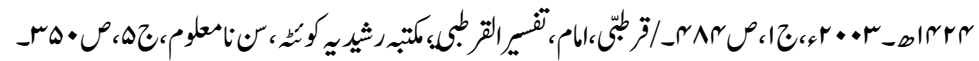

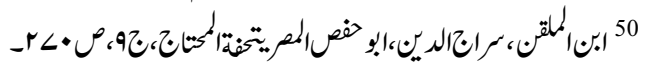
- 51 52

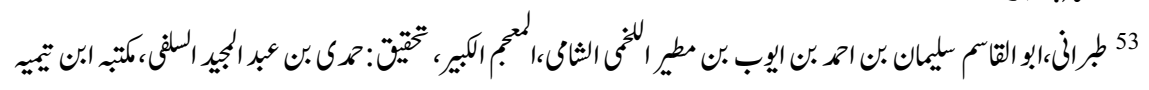

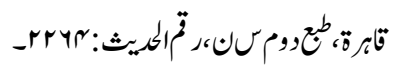

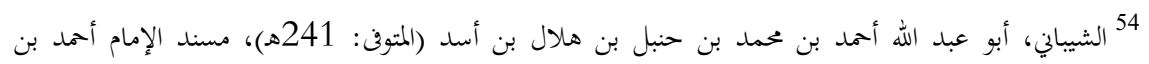

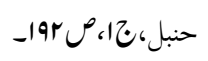
-91: 95

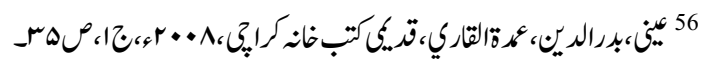

